\title{
Microwave assisted synthesis of polynuclear Ni(II) complexes
}

Lidia Rosado Piquer, ${ }^{a, b}$ E. Carolina Sañudo ${ }^{a, b *}$

Published in 2019, please cite as: Rosado Piquer, L.; Sañudo, E. C. Microwave Assisted Synthesis of Polynuclear Ni(II) Complexes. Polyhedron 2019, 169, 195-201

DOI: https://doi.org/10.1016/j.poly.2019.05.011

a Secció de Química Inorgànica, Departament de Química Inorgànica i orgànica, Facultat de Química, Universitat de Barcelona. C/Martí i Franqués 1-11, Barcelona 08028 Spain; ${ }^{b}$ Institut de Nanociència i Nanotecnologia (IN2UB), Universitat de Barcelona. C/Martí i Franqués 1-11, Barcelona 08028 Spain

\begin{abstract}
In this paper we test a solvent-free microwave assisted synthesis method with a known $\mathrm{Ni}_{7}$ complex, $\left[\mathrm{Ni}_{7}(\mathrm{chp})_{12}(\mathrm{OH})_{2}\left(\mathrm{CH}_{3} \mathrm{OH}\right)_{6}\right](2)$, and then extended the method to a more complex ligand system. We prepare two new trinuclear $\mathrm{Ni}(\mathrm{II})$ complexes $\left(\left[\mathrm{Ni}_{3}(\mathrm{chp})_{4}(\mathrm{tBuSALOH})_{2}(\mathrm{MeOH})_{5}\right](4)\right.$ and $\left.\left[\mathrm{Ni}_{3}(\mathrm{chp})_{4}(\mathrm{iPrSALOH})_{2}(\mathrm{MeOH})_{6}\right](5)\right)$ and report here their characterization and magnetic properties.
\end{abstract}

\section{Introduction}

The synthesis of high nuclearity coordination complexes is an area where design and serendipity struggle. Serendipitous self-assembly ${ }^{1,2}$ is at the heart of the mechanism of formation of most high nuclearity transition metal complexes. It is often impossible to predict the outcome of a reaction and single-crystal X-ray characterization is key in order to ascertain the nature of the product. In solution it is often the case that several species may form and one or more than one might precipitate or crystallize. There are few examples when complex molecules co-crystallize like the iron clusters reported by Aromí et al, where a dimer of $\mathrm{Fe}_{4}$ butterfly type complexes co-crystallizes with a dimer of $\mathrm{Fe}_{3}$ complexes. Carefully controlling the system allows the crystallization of either the $\mathrm{Fe}_{4}$ butterfly dimer or the dimer of $\mathrm{Fe}_{3}$ complexes. ${ }^{3}$ 
In a world were waste management is very important and the chemical industries are subject to strict waste management policies (for EU: http://ec.europa.eu/environment/waste/index.htm), synthetic methods that reduce waste generation should be key. In particular this is even more important for the possible technological application of coordination complexes, in the so-called molecular spintronics approach to information storage and processing. ${ }^{4-6}$ Syntheses without solvents, in a melt state ${ }^{7-11}$ or forcing sublimation of a species ${ }^{12}$ have been a good route to high nuclearity complexes. Of particular relevance to spintronics is the archetypical mononuclear single molecule magnet ( $\mathrm{SMM}) \mathrm{TbPc}_{2},{ }^{13}$ synthesized by conventional heating over long periods of time and that often produce mixtures of products and require tedious purification methods. ${ }^{14,15}$ In general, for these synthesis yields are usually poor and reproducibility might be problematic in some cases. On the other hand, these kind of reactions are effective in providing access to high nuclearity complexes.

Single ion anisotropy for $\mathrm{Ni}(\mathrm{II})$ in an axial coordination environment can be large. ${ }^{16,17}$ In some cases, this might lead to slow relaxation of the magnetization and SMM behavior. The first Ni(II) SMM was reported in 1994, it was a dodecanuclear species of formula $\left[\mathrm{Ni}_{12}(\mathrm{chp})_{12}\left(\mathrm{O}_{2} \mathrm{CMe}\right)_{12}(\text { thf })_{6}\left(\mathrm{H}_{2} \mathrm{O}\right)_{6}\right] .{ }^{18}$ The molecule has a large spin ground state $(\mathrm{S}=12)$ and small axial magnetic anisotropy $\left(D=-0.05 \mathrm{~cm}^{-1}\right)$ setting the standard for Nil(II) SMMs, which are usually characterized by very low blocking temperatures. ${ }^{19,20}$

In order to tackle the lack of reproducibility observed in the particular case of a $\mathrm{Ni}_{7}$ complex reported by Winpenny ${ }^{8,21}$ we decided to undertake such 'melt' reactions in the microwave reactor. There is already a report of $\mathrm{TbPc}_{2}{ }^{22}$ prepared using microwaves to improve yield and avoid mixtures. Microwave assisted synthesis has been used with quite a lot of success to prepare high-nuclearity complexes by Brechin and coworkers ${ }^{23,24}$ and by us, ${ }^{25-28}$ among others. ${ }^{29-31}$

In this paper we report the use of solvent free microwave assisted synthesis to prepare $\mathrm{Ni}(I I)$ complexes with a simple ligand system.

\section{Experimental}

All solvents and reagents were acquired form commercial sources and used as received. Microwave assisted reactions were performed in a CEM Discover reactor. chp is 
deprotonated 6-chloro-2-hydroxypyridine $\left(\mathrm{C}_{5} \mathrm{H}_{3} \mathrm{CINO}\right)$, tBuSALOH is monodeprotonated 3,5-di-tert-butylsalycilic acid (tBuSALOH ${ }_{2}, \mathrm{C}_{15} \mathrm{H}_{21} \mathrm{O}_{3}$ ) and iPrSALOH is monodeprotonated 3,5-di-isopropyl-salycilic acid (iPrSALOH $\left.{ }_{2}, \mathrm{C}_{13} \mathrm{H}_{17} \mathrm{O}_{3}\right)$.

[Ni(OH) $)_{2} \cdot \mathbf{x H}_{2} \mathrm{O}(1): \mathrm{NiCl}_{2} \cdot 6 \mathrm{H}_{2} \mathrm{O}(2.59 \mathrm{~g}, 10.88 \mathrm{mmol})$ and $\mathrm{NaOH}$ are mixed in $50 \mathrm{ml}$ of water. The reaction is stirred for 10 minutes. A green precipitate is filtered and dried under vacuum for at least 8 hours. Yield is quantitative. IR $\left(\mathrm{KBr}, \mathrm{cm}^{-1}\right): 3488(\mathrm{~s}$, broad), $1645(\mathrm{~m}), 1462(\mathrm{~m}), 1369(\mathrm{~m}), 655$ (s, broad), $416(\mathrm{~s})$.

\section{$\left[\mathrm{Ni}_{7}(\mathrm{chp})_{12}(\mathrm{OH})_{2}\left(\mathrm{CH}_{3} \mathrm{OH}\right)_{6}\right](2)\left(\mathrm{Ni}_{7}\right)$}

Fresh 1 (0.4 g, $4.3 \mathrm{mmol})$ and chp $(0.562 \mathrm{~g}, 4.3 \mathrm{mmol})$ are mixed in a microwave reactor cavity. A microwave pulse of $150 \mathrm{~W}$ is applied and the reaction kept at $150^{\circ} \mathrm{C}$ for 10 minutes. The solid obtained is dried in vacuum for 2 hours. The dried solid is extracted with $10 \mathrm{~mL}$ of $\mathrm{MeOH} / \mathrm{MeCN}$ (1:1 en volum) while heating is applied. The suspension is filtered while hot and the solid discarded. Slow evaporation of the liquor results in green crystals of complex 2 after circa. 15 days.

Yield: 8\% (52 mg). Elemental analyses calculated for $\mathrm{C}_{66} \mathrm{H}_{62} \mathrm{Cl}_{12} \mathrm{~N}_{12} \mathrm{Ni}_{7} \mathrm{O}_{20}$ : C, 36.54\%; $\mathrm{N}$, 7.75\%; H, 2.88\%. Experimental elemental analyses: $\mathrm{C}, 35.82 \% ; \mathrm{N}, 7.76 \% ; \mathrm{H}, 2.68 \%$. IR $\left(\mathrm{KBr}, \mathrm{cm}^{-1}\right)$ : 3092 (m, broad), 2791 (m, broad), 1596 (s), 1539 (s), 1447 (s), 1341 (s), 1248 (m), $1172(\mathrm{~m}), 1002(\mathrm{~s}), 937(\mathrm{~m}), 788(\mathrm{~s}), 731(\mathrm{~m}), 701(\mathrm{~m})$.

\section{$\left[\mathrm{Ni}\left(\mathrm{H}_{2} \mathrm{O}\right)_{2}(\mathrm{chp})_{2}\right](3)\left(\mathrm{Ni}_{1}\right)$}

Fresh 1 (1.1 g, $8.4 \mathrm{mmol})$ and chp $(1.088 \mathrm{~g}, 8.4 \mathrm{mmol})$ are mixed in a Schlenck flask and heated under $\mathrm{N}_{2}$ at $130^{\circ} \mathrm{C}$ for 2 hours. The green solid is extracted with $\mathrm{MeCN} / \mathrm{MeOH}$ (1:1) while heating is applied. The suspension is filtered while hot and the solid discarded. Slow evaporation of the liquor results in deep green crystals of complex $\mathbf{3}$ after circa. 25 days.

Yield <5\% (55 mg). Elemental analyses calculated for $\mathrm{C}_{10} \mathrm{H}_{10} \mathrm{Cl}_{2} \mathrm{~N}_{2} \mathrm{NiO}_{4}$ : C, 34.3\%; $\mathrm{N}, 8.0 \%$; $\mathrm{H}, 2.8 \%$. Experimental elemental analyses: $\mathrm{C}, 34.6 \% ; \mathrm{N}, 7.9 \% ; \mathrm{H}, 2.8 \% . \mathrm{IR}\left(\mathrm{KBr}, \mathrm{cm}^{-1}\right)$ : 3214 (s, broad), 1602 (s), 1537 (s), 1453 (s), 1345 (s), 1241 (m), 1167 (s), 1003 (s), 936 (s), $856(\mathrm{~m}), 789(\mathrm{~s}), 734(\mathrm{~s}), 702(\mathrm{~m}), 667(\mathrm{~m}), 608(\mathrm{~m})$. 


\section{$\left[\mathrm{Ni}_{3}(\mathrm{chp})_{4}(\mathrm{tBuSALOH})_{2}(\mathrm{MeOH})_{5}\right](4)\left(\mathrm{Ni}_{3} \mathrm{tBu}\right)$}

Fresh 1 (0.203 g, $2.176 \mathrm{mmol})$, chp $(0.281 \mathrm{~g}, 2.176 \mathrm{mmol})$ and tBuSALOH 2 (181.7 mg, $0.726 \mathrm{mmol}$ ) are mixed in the microwave reactor cavity. A microwave pulse of $150 \mathrm{~W}$ is applied and the reaction kept at $170^{\circ} \mathrm{C}$ for 10 minutes. The solid is extracted with $10 \mathrm{~mL}$ of $\mathrm{MeOH} / \mathrm{MeCN}$ (1:1 volume) while heating is applied. The suspension is filtered while hot and the solid discarded. Slow evaporation of the liquor results in green crystals of complex 4 after circa. 3 days.

Yield: $44 \%$ (0.214 g). Calculated elemental analyses for $\mathrm{C}_{55} \mathrm{H}_{74} \mathrm{Cl}_{4} \mathrm{~N}_{4} \mathrm{Ni}_{3} \mathrm{O}_{15}: \mathrm{C}, 49.0 \% ; \mathrm{N}$, 4.2\%; $\mathrm{H}, 5.6 \%$. Experimental elemental analyses: $\mathrm{C}, 49.1 \% ; \mathrm{N}, 4.2 \% ; \mathrm{H}, 5.6 \%$. IR $\left(\mathrm{KBr}, \mathrm{cm}^{-}\right.$ 1): 3339 (m, broad), 2956 (s), 2522 (m, broad), 1596 (s), 1539 (s), 1435 (s), 1386 (s), 1331 (s), $1292(\mathrm{~s}), 1244(\mathrm{~s}), 1219(\mathrm{~m}), 1202(\mathrm{~m}), 1170(\mathrm{~s}), 1151(\mathrm{~m}), 1023(\mathrm{~s}), 998(\mathrm{~s}), 923(\mathrm{~s})$, $814(\mathrm{~m}), 784(\mathrm{~s}), 748(\mathrm{~m}), 727(\mathrm{~m}), 704(\mathrm{~m})$.

\section{$\left[\mathrm{Ni}_{3}(\mathrm{chp})_{4}(\mathrm{iPrSALOH})_{2}(\mathrm{MeOH})_{6}\right](5)\left(\mathrm{Ni}_{3} \mathrm{iPr}\right)$}

Fresh 1 (0.203 g, $2.176 \mathrm{mmol})$, chp $(0.281 \mathrm{~g}, 2.176 \mathrm{mmol})$ and iPrSALOH $2(161.38 \mathrm{mg}$, $0.726 \mathrm{mmol}$ ) are mixed in the microwave reactor cavity. A microwave pulse of $150 \mathrm{~W}$ is applied and the reaction kept at $150^{\circ} \mathrm{C}$ for 10 minutes. The solid is extracted with $10 \mathrm{~mL}$ of $\mathrm{MeOH} / \mathrm{MeCN}$ (1:1 volume) while heating is applied. The suspension is filtered while hot and the solid discarded. Slow evaporation of the liquor results in green crystals of complex 5 after circa. 4 days.

Yield: $27 \%$ (0.130 g). Calculated elemental analyses for $\mathrm{C}_{52} \mathrm{H}_{70} \mathrm{Cl}_{4} \mathrm{~N}_{4} \mathrm{Ni}_{3} \mathrm{O}_{16}: \mathrm{C}, 47.1 \%$; , 4.2\%; $\mathrm{H}, 5.3 \%$. Experimental elemental analyses: $\mathrm{C}, 47.1 \% ; \mathrm{N}, 4.2 \% ; \mathrm{H}, 5.0 \%$. IR $\left(\mathrm{KBr}, \mathrm{cm}^{-}\right.$ 1): 3332 (m, broad), 2956 (s), 2522 (m, broad), 1596 (s), 1538 (s), 1437 (s), 1392 (s), 1330 (s), 1243 (s), 1169 (s), 1072 (m), 1022 (s), 998 (s), 923 (s), 872 (w), 813 (s), 785 (s), 753 (m), $704(m), 638(w), 617(m), 478(m), 424(m)$.

X-Ray diffraction data for complexes 3, 4, 5 were collected on a Bruker APEXII SMART diffractometer using Molybdenum Ka microfocus $(\lambda=0.71073 \AA$ ) radiation source. Single crystal diffraction data for $\mathbf{2}$ were collected at the Advanced Light Source station, at Berkeley (USA) ( $T=173 \mathrm{~K}, \lambda=0.71073 \AA \AA$ ). The structures were solved by Patterson or intrinsic phasing methods (SHELXS2013 and SHELXT) and refined on $\mathrm{F}^{2}$ (SHELXL-2013). Hydrogen atoms were included on calculated positions, riding on their carrier atoms. 
Elemental analyses (CHN) were performed at Servei de Microanàlisi in CSIC (Consell Superior d'Investigacions Científiques). Infrared spectra were collected on $\mathrm{KBr}$ pellets on an AVATAR 330 FT-IR at Departament de Química Inorgànica, Universitat de Barcelona.

Magnetic measurements were performed at the Unitat de Mesures Magnètiques of the Universitat de Barcelona on a Quantum Design SQUID MPMS-XL magnetometer equipped with a $5 \mathrm{~T}$ magnet. Diamagnetic corrections for the sample holder and for the sample using Pascal's constants were applied. Hysteresis measurements were performed with an array of micro-SQUIDs. This magnetometer works in the temperature range of 0.04 to $5 \mathrm{~K}$ and in fields up to $1.4 \mathrm{~T}$ with sweeping rates as high as $0.28 \mathrm{~T} \mathrm{~s}^{-1}$.

\section{Results}

We reproduced the synthesis reported by Brechin and Winpenny ${ }^{8}$ for complex 2, $\left[\mathrm{Ni}_{7}(\mathrm{chp})_{12}(\mathrm{OH})_{2}\left(\mathrm{CH}_{3} \mathrm{OH}\right)_{6}\right]$, with various results: complex 2: $\mathrm{Ni}_{7}$ was obtained with very low yield and often contaminated by a $\mathrm{Ni}(\mathrm{II})$ monomer that was identified as complex $\mathbf{3}$, $\left[\mathrm{Ni}\left(\mathrm{H}_{2} \mathrm{O}\right)_{2}(\mathrm{chp})_{2}\right]$, a monomer of $\mathrm{Ni}(\mathrm{II})$ with two chp ligands and two aqua ligands. The starting material for this reaction was nickel hydroxide, freshly prepared. In fact, an infra-red analysis of the discarded precipitate showed broad intense bands in the 400 and $600 \mathrm{~cm}^{-1}$ region, in accord with metal oxides. Taking the reaction to the microwave cavity resulted in a green paste that was then treated with $\mathrm{MeOH} / \mathrm{MeCN}$ and crystals of complex 2: $\mathrm{Ni}_{7}$ were obtained in a reproducible manner. The choice of the chp ligand is not trivial, since its easily attainable melting point makes it ideal for this kind of synthesis: the melted ligand or ligands are the medium where diffusion happens and reaction takes place. Figure 1 shows the structure of the ligands and their melting points. Introduction of a carboxylato ligand, in the form of the corresponding acid in the reaction medium, was checked by using tow derivatives of salicylic acid, with tert-butyl and iso-propyl substituents. These carboxylic acids have easily attainable melting points and are good ligands for high-nuclearity complexes. The treatment of the solid obtained from the microwave assisted reaction resulted in green solutions and some solid that did not dissolve. This solid was discarded. Slow evaporation of the green solutions gave nice single crystals of $\left[\mathrm{Ni}_{3}(\mathrm{chp})_{4}(\mathrm{tBuSALOH})_{2}(\mathrm{MeOH})_{5}\right]$ (4) and $\left[\mathrm{Ni}_{3}(\mathrm{chp})_{4}(\mathrm{iPrSALOH})_{2}(\mathrm{MeOH})_{6}\right](5)$. The two species differ in the number of coordinated 
$\mathrm{MeOH}$ molecules and in the coordination of the chp ligands (vide infra). The reactions were very reproducible and no other byproducts were obtained. Microwave assisted synthesis has proven a fast reaction method that allows access to high-nulearity species in a reproducible manner.<smiles>CC(C)(C)c1cc(C(=O)O)c(O)c(C(C)(C)C)c1</smiles>

tBuSALOH<smiles>Oc1cccc(Cl)n1</smiles>

chp<smiles>CC(C)c1cc(C(=O)O)c(O)c(C(C)C)c1</smiles>

$\mathrm{iPrSALOH}_{2}$

Melting point (으)

chp $\quad 128-130$

tBuSALOH $\quad 157-162$

iPrSALOH $_{2} \quad 113-115$

Figure 1. Structure of the ligands and their melting points.

\section{Description of crystal structures}

Table 1 shows the data collection and crystallographic parameters for $\mathbf{2}: \mathrm{Ni}_{7}, \mathbf{3}: \mathrm{Ni}_{1}, \mathbf{4}$ : $\mathrm{Ni}_{3} \mathrm{tBu}$ and 5: $\mathrm{Ni}_{3} \mathrm{iPr}$.

Table 1. Data collection and crystallographic parameters for complexes 2: $\mathrm{Ni}_{7}, \mathbf{3}: \mathrm{Ni}_{1}, \mathbf{4 :} \mathrm{Ni}_{3} \mathrm{tBu}$ and 5: $\mathrm{Ni}_{3} \mathrm{iPr}$.

\begin{tabular}{lllll}
\hline & $\mathbf{2}$ & $\mathbf{3}$ & $\mathbf{4}$ & $\mathbf{5}$ \\
\hline Formula & $\mathrm{Ni}_{7}$ & $\mathrm{Ni}_{1}$ & $\mathrm{Ni}_{3} \mathrm{tBu}$ & $\mathbf{N i} \mathbf{P i}_{3}$ \\
$\mathbf{M W}$ & $\mathrm{C}_{66} \mathrm{H}_{62} \mathrm{Cl}_{12} \mathrm{~N}_{12} \mathrm{Ni}_{7} \mathrm{O}_{20}$ & $\mathrm{C}_{10} \mathrm{H}_{6} \mathrm{Cl}_{2} \mathrm{~N}_{2} \mathrm{NiO}_{4}$ & $\mathrm{C}_{55} \mathrm{H}_{74} \mathrm{Cl}_{4} \mathrm{~N}_{4} \mathrm{Ni}_{3} \mathrm{O}_{15}$ & $\mathrm{C}_{52} \mathrm{H}_{70} \mathrm{Cl}_{4} \mathrm{~N}_{4} \mathrm{Ni}_{3} \mathrm{O}_{16}$ \\
Crystal & 2179.64 & 347.78 & 1344.20 & 1325.05 \\
system & monoclinic & monoclinic & triclinic & triclinic \\
Space group & $\mathrm{P} 2{ }_{1} / \mathrm{n}$ & & & \\
a/A & $12.4654(13)$ & $11.7180(13)$ & $11.4853(2)$ & $\mathrm{P}-1$ \\
b/Å & $19.813(2)$ & $5.3087(6)$ & $12.9875(3)$ & $11.463(3)$ \\
\hline
\end{tabular}




\begin{tabular}{|c|c|c|c|c|}
\hline$c / \AA ̊$ & $17.5510(19)$ & $10.6786(11)$ & $22.2963(5)$ & $12.721(4)$ \\
\hline$\alpha /^{\circ}$ & 90 & 90 & $75.6450(10)$ & $91.78(2)$ \\
\hline$\beta /^{\circ}$ & $106.4440(14)$ & $106.874(7)$ & $89.8420(10)$ & $109.585(18)$ \\
\hline$v /^{\circ}$ & 90 & 90 & $88.5890(10)$ & $91.551(17)$ \\
\hline Volume/ $\AA^{3}$ & $4157.3(8)$ & $635.69(12)$ & $3221.00(12)$ & $1572.0(8)$ \\
\hline z & 2 & 2 & 2 & 1 \\
\hline Reflections & 45744 & 5860 & 64470 & 14033 \\
\hline $\mathrm{mu} / \mathrm{mm}^{-1}$ & 2.011 & 1.955 & 1.097 & 1.124 \\
\hline$R$ (int) & 0.0439 & 0.0430 & 0.0410 & 0.0726 \\
\hline$R$ indexes & $\mathrm{R}_{1}=0.0367$ & $\mathrm{R}_{1}=0.0372$ & $\mathrm{R}_{1}=0.0447$ & $\mathrm{R}_{1}=0.0793 w \mathrm{R}_{2}=$ \\
\hline$[1 \geq 2 \sigma(1)]$ & $w R_{2}=0.1021$ & $\mathrm{wR}_{2}=0.1104$ & $w R_{2}=0.1099$ & 0.2159 \\
\hline $\mathbf{R}$ indexes (all & $R_{1}=0.0398$ & $R_{1}=0.0494$ & $\mathrm{R}_{1}=0.0872$ & $\mathrm{R}_{1}=0.1271 \mathrm{wR}_{2}=$ \\
\hline data) & $w R_{2}=0.1041$ & $w R_{2}=0.1229$ & $w R_{2}=0.1277$ & 0.2523 \\
\hline $\mathrm{T} / \mathrm{K}$ & 173 & 100 & 293 & 293 \\
\hline
\end{tabular}<smiles>[M]OC(O[M])c1cc([R])cc([R])c1O</smiles><smiles>[M]O[c-]1n2c(Cl)cccc2[n+]1[M]</smiles>
$\mu: \eta^{2}: \eta^{1}$ chelating<smiles>[M]Oc1cccc(Cl)n1</smiles>

Scheme 1. Binding modes of the chp and carboxylato ligands.

As mentioned in the synthesis section, complex $2: \mathrm{Ni}_{7}$ was usually obtained contaminated with a $\mathrm{Ni}(\mathrm{II})$ monomer, complex $3: \mathrm{Ni}_{1}$, or unreacted oxides. For the microwave assisted reactions we studied several crystals from each batch both at our in-house diffractometer and at Berkeley ALS synchrotron radiation source. In all cases 
the unit cell and the structure obtained were those of complex 2: $\mathrm{Ni}_{7}$. The structure of complex $\mathbf{2}: \mathrm{Ni}_{7}$ is shown in Figure 2. This is a known structure previously reported by Winpenny et $\mathrm{al}^{8}$, so it will not be described in detail here. All $\mathrm{Ni}$ are $\mathrm{Ni}(\mathrm{II})$ in complex 2: $\mathrm{Ni}_{7}$, hexacoordinated in a distorted octahedral fashion. The core can be described as two distorted tetrahedral $\mathrm{Ni}_{4}$ units sharing one vertex, as shown in Figure 2. The $\mathrm{Ni}_{3}$ units are bridged by $\mathrm{OH}$ - groups, the protonation level is established calculating the bond valence sum (BVS). ${ }^{32}$ The same reaction performed in normal bench-top conditions results in mixtures of complex 2: $\mathrm{Ni}_{7}$ and complex 3: $\mathrm{Ni}_{1}$. Complex 3: $\mathrm{Ni}_{1}$ is a mononuclear $\mathrm{Ni}(I I)$ complex with two chelating chp ligands and two coordinated water molecules that are inv $2.6 \AA) \cdot{ }^{33}$ BVS of the terminal oxygen atoms (
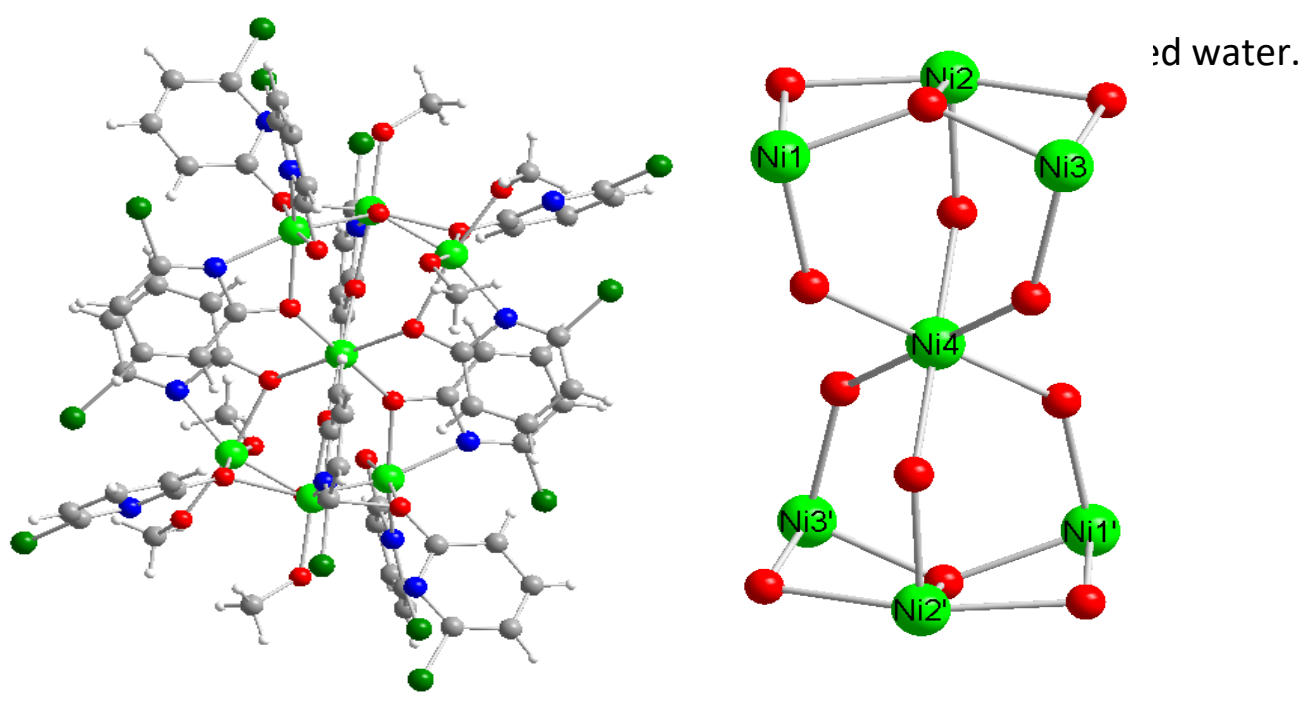

Figure 2. Crystal structure and core of complex 2: $\mathrm{Ni}_{7}$.
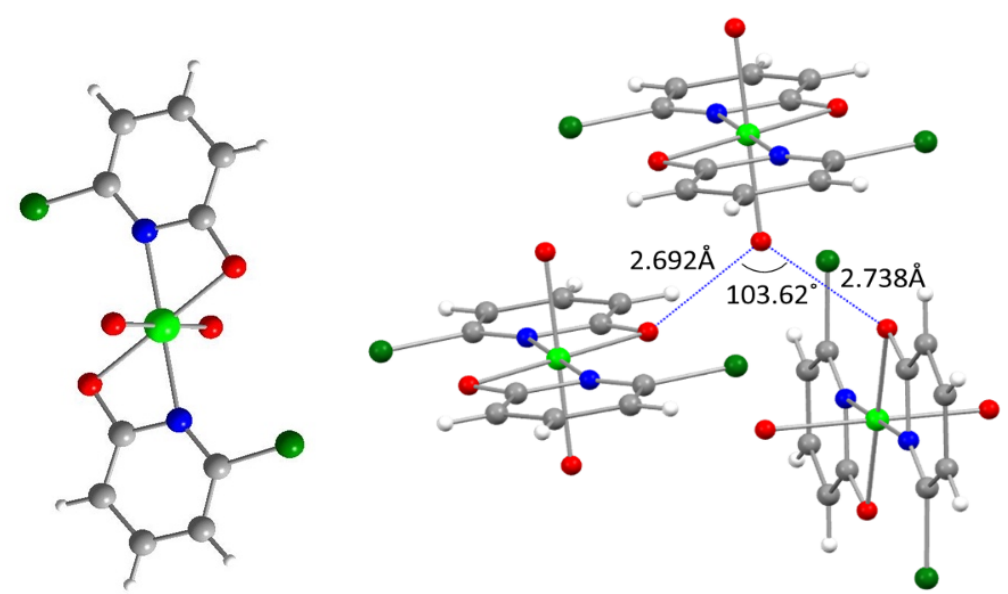
Figure 3. Crystal structure and packing of complex $\mathbf{3}: \mathrm{Ni}_{1}$, showing the intermolecular interaction via $\mathrm{H}$-bonding of one chp oxygen and the coordinated water.

When a carboxylic acid is introduced in the reaction mixture, a linear $\mathrm{Ni}_{3}$ complex is formed. The coordination modes of chp found in complexes 4: $\mathrm{Ni}_{3} \mathrm{tBu}$ and 5: $\mathrm{Ni}_{3} \mathrm{iPr}$ are found in Scheme 1. They are the same as those found in complex 2. Complexes 4: $\mathrm{Ni}_{3} \mathrm{tBu}$ and 5 consist of a linear arrangement of three $\mathrm{Ni}(\mathrm{II})$ ions, as shown in Figure 4 . All metal centers are hexacoordinated in a distorted octahedral fashion. Each pair of $\mathrm{Ni}(\mathrm{II})$ ions are bridged by one syn,syn-carboxylato groups from tBuSALOH in 4: $\mathrm{Ni}_{3} \mathrm{tBu}$ and iPrSALOH in 5: $\mathrm{Ni}_{3}$ iPr. The hydroxyl group of the ligand does not participate in metal bonding in either 4: $\mathrm{Ni}_{3} \mathrm{tBu}$ or 5 : $\mathrm{Ni}_{3} i \mathrm{Pr}$. There are four chp ligands in 4: $\mathrm{Ni}_{3} \mathrm{HB}$, three of them using the oxygen atom to bridge two Ni(II) ions in coordination mode III (Scheme 1), and one in coordination mode II (Scheme 1) that uses the pyridine nitrogen to chelate one $\mathrm{Ni}(\mathrm{II})$ ion. In complex $\mathbf{5}$ : $\mathrm{Ni}_{3} \mathrm{iPr}$ the four chp ligands are in the same binding mode: bridging two $\mathrm{Ni}(\mathrm{II})$ ions using the oxygen atom, coordination mode III (Scheme 1). The two external $\mathrm{Ni}(\mathrm{II})$ ions in the $\mathrm{Ni}_{3}$ unit complete their coordination sphere with coordinated $\mathrm{MeOH}$. For complex 4: $\mathrm{Ni}_{3} \mathrm{tBu}$ the two $\mathrm{Ni}(\mathrm{II}) \mathrm{Ni}(2)$ and $\mathrm{Ni}(3)$ are crystallographically distinct, $\mathrm{Ni}(2)$ coordinates to the chelating chp (coordination mode II in Scheme 1) and to two $\mathrm{MeOH}$ ligands while $\mathrm{Ni}(3)$ completes the octahedral coordination with three $\mathrm{MeOH}$ ligands. For complex 5 : $\mathrm{Ni}_{3} i \mathrm{Pr}$, the central $\mathrm{Ni}(\mathrm{II})$ ion $\mathrm{Ni}(1)$ is sitting in a crystallographic inversion center and the two terminal $\mathrm{Ni}(\mathrm{II})$ ions are $\mathrm{Ni}(2)$ and $\mathrm{Ni}\left(2^{\prime}\right)$, related by symmetry. Both $\mathrm{Ni}(2)$ and $\mathrm{Ni}\left(2^{\prime}\right)$ complete their coordination sphere with three $\mathrm{MeOH}$ ligands.

Table 2. Bond Valence Sum (BVS) for complexes 2-5

\begin{tabular}{lcccc}
\hline & $\mathbf{2 : ~} \mathbf{N i}_{\mathbf{7}}$ & $\mathbf{3 :} \mathbf{N i}_{\mathbf{1}}$ & $\mathbf{4 :} \mathbf{N i}_{3} \mathbf{t B u}$ & $\mathbf{5 : ~} \mathbf{N i}_{3} \mathbf{i P r}$ \\
\hline $\mathrm{Ni} 1$ & 1.93 & 1.95 & 2.03 & 2.03 \\
$\mathrm{Ni} 2$ & 2.00 & & 2.10 & 2.04 \\
$\mathrm{Ni} 3$ & 2.00 & & 2.06 & \\
$\mathrm{Ni} 4$ & 2.06 & & & \\
\hline
\end{tabular}



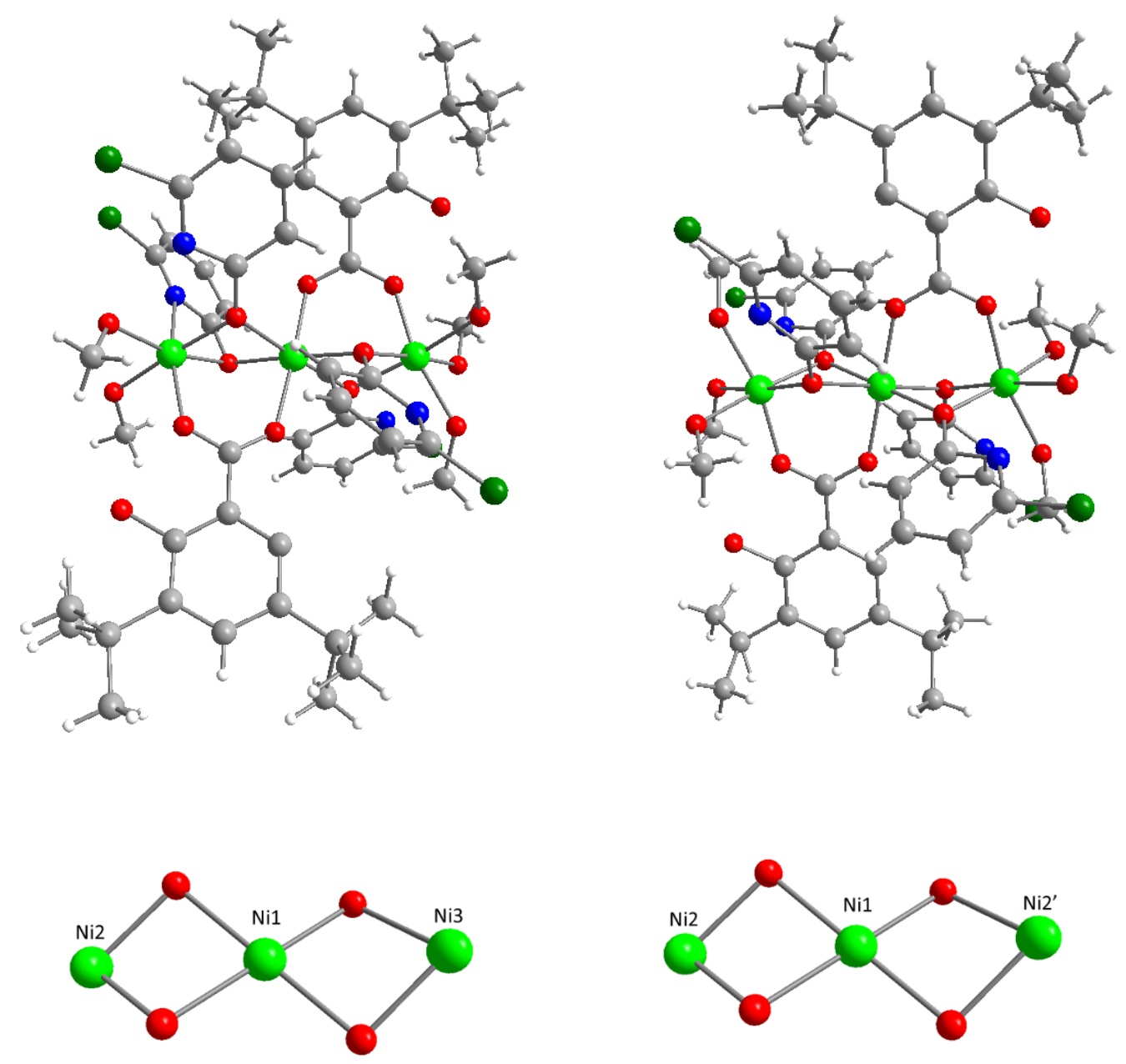

Figure 4. Crystal structures of 4: $\mathrm{Ni}_{3} \mathrm{tBu}$ (left) and 5: $\mathrm{Ni}_{3} \mathrm{iPr}$ (right).

\section{Magnetic properties}

The magnetic susceptibility of complex 2: $\mathrm{Ni}_{7}$ was measured at two different applied fields (300 and 5000 Oe) and is shown in Figure 5 as $\chi \top$ vs. T plot. Between 2-300 K data were collected with an applied field of 5000 Oe and below $25 \mathrm{~K}$ data were collected with an applied field of 300 Oe. The susceptibility is clearly field dependent. The $\chi^{\top}$ product at $300 \mathrm{~K}$ has a value of $8.47 \mathrm{~cm}^{3} \mathrm{~K} \mathrm{~mol}^{-1}$, in agreement for seven isolated $\mathrm{Ni}(\mathrm{II})$ ions with $\mathrm{S}=1$ and $\mathrm{g}=2.2$. The susceptibility decreases steadily down to $30 \mathrm{~K}$, as expected for dominant antiferromagnetic interactions. There is a small plateau at a $\chi^{\top}$ product value 
of $4.5 \mathrm{~cm}^{3} \mathrm{~K} \mathrm{~mol}^{-1}$ and then the a $\chi^{\top}$ product drops sharply to a non-zero value of $2 \mathrm{~cm}^{3}$ $\mathrm{K} \mathrm{mol}^{-1}$.

The magnetization vs. field plot at $2 \mathrm{~K}$ is shown in Figure 6 . Clearly, saturation is not reached even at the highest field of $5 \mathrm{~T}$. The shape of the curve is typical of Zeeman population of a large number of excited states with larger $\mathrm{S}$ than the ground state.

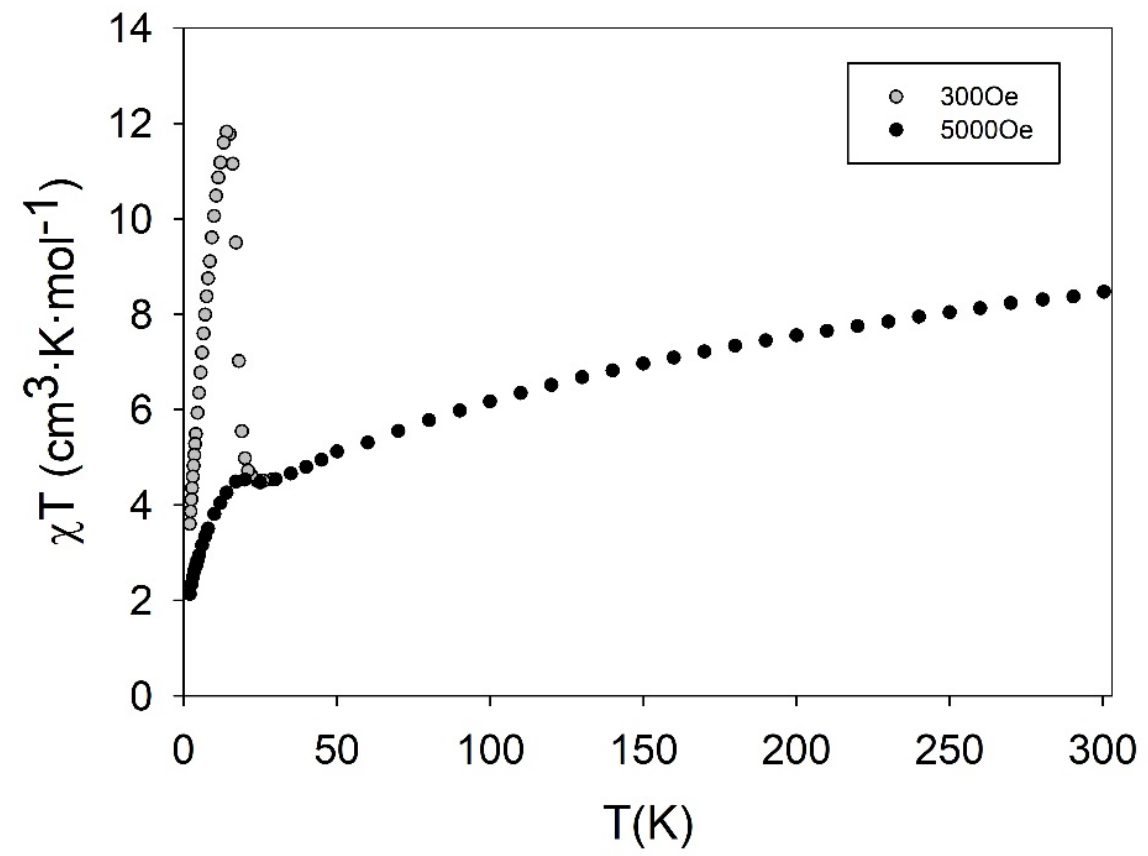

Figure 5. Magnetic susceptibility for complex 2: $\mathrm{Ni}_{7}$ shown as a $\chi^{\top} \mathrm{vs}$. $\mathrm{T}$ plot at the indicated magnetic fields.

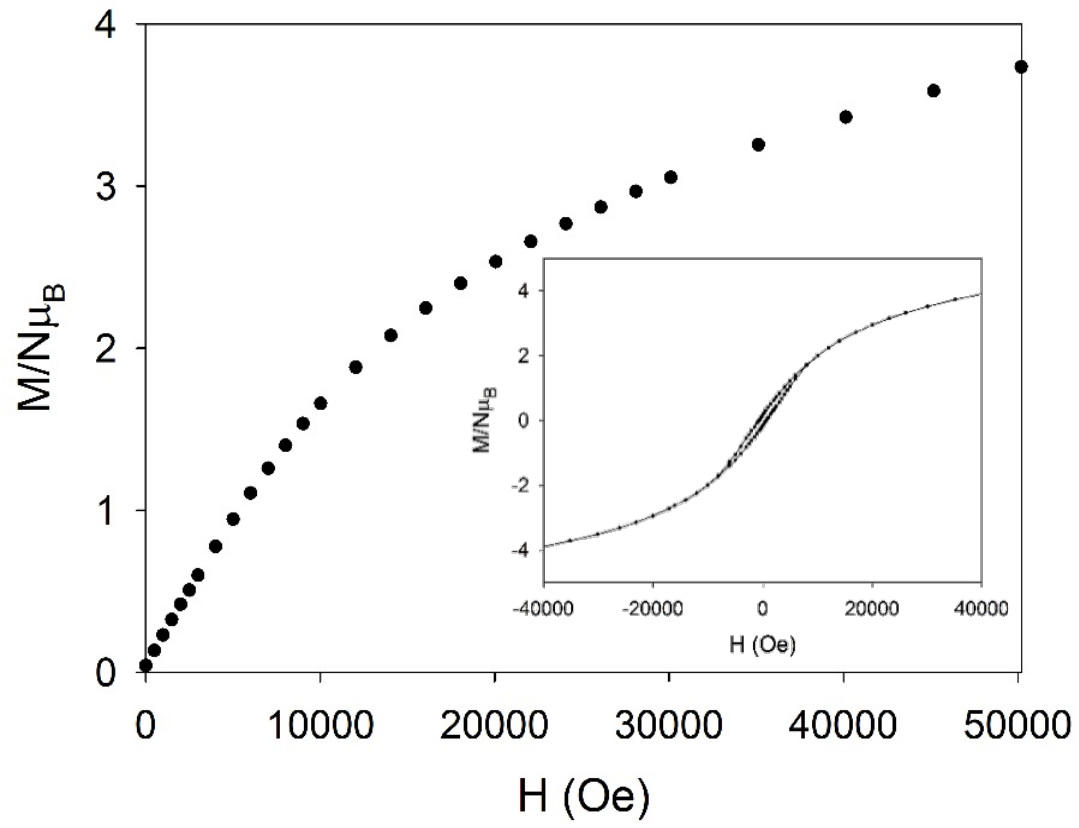


Figure 6. Magnetization vs field plot at $2 \mathrm{~K}$ for complex 2: $\mathrm{Ni}_{7}$. The inset shows a hysteresis loop at the same temperature for complex $2: \mathrm{Ni}_{7}$.

The disposition of the seven $\mathrm{Ni}(\mathrm{II})$ ions in complex 2: $\mathrm{Ni}_{7}$ as two tetrahedra sharing a vertex results in a spin frustrated system if all pairwise magnetic exchange interactions are antiferromagnetic as expected for the observed $\mathrm{Ni}-\mathrm{OH}-\mathrm{Ni}$ angles $\left(98.92^{\circ}, 108.89^{\circ}\right.$ and $\left.130.12^{\circ}\right)$ and the Ni-O-Ni angles $\left(133.80^{\circ}, 134.90^{\circ}\right.$ and $\left.136.14^{\circ}\right)$. Garlatti et al. studied the magnetic properties of this complex and used a simple model with two antiferromagnetic exchange constants. This results in the ground state $S=1$ that includes nine distinct multiplets, for a total degeneracy of 27 , resulting in a spin manifold. ${ }^{21}$ We observed a narrow hysteresis of the magnetization vs. field for a pure, crushed, crystalline sample of complex 2: $\mathrm{Ni}_{7}$ at $2 \mathrm{~K}$ (Figure 6) and out-of-phase ac magnetic susceptibility frequency dependent peaks (Figure 7).
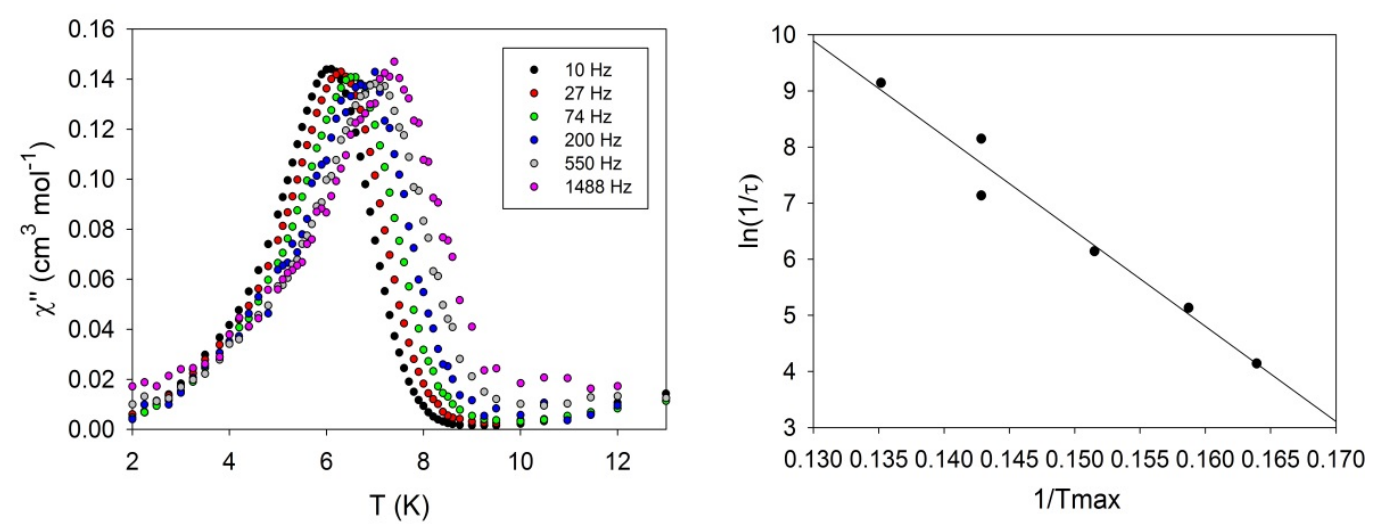

Figure 7. Out-of-phase ac magnetic susceptibility for complex 2: $\mathrm{Ni}_{7}$ at the indicated frequencies and Arrhenius plot for the ac data.

Clearly, the out-of-phase signal is not the typical of a transition metal SMM like $\mathrm{Mn}_{12 .}{ }^{34,35}$ When the relaxation process is studied using the Arrhenius equation, $\tau=\tau_{o} e^{-U e f f / k T}$ 
the values obtained are $U_{\text {eff }}=169.6 \mathrm{~K} \mathrm{i} \tau_{0}=1.3 \cdot 10^{-14} \mathrm{~s}^{-1}$. The value for the pre-exponential factor is not that of an SMM and it is better suited for the relaxation of the free electron. Similar values are found for spin-glasses, where frustration and disorder play a key role. ${ }^{36,37}$ Similar systems with $\mathrm{Ni}(\mathrm{II})$ that show AC peaks due to spin frustration have been reported for $\mathrm{Ni}_{10}$ supertetrahedral complexes. ${ }^{38,39}$ The Mydosh parameter ${ }^{37,40}$ was calculated. Using the formula $F=\left(\Delta T_{M} / T_{M}\right) /(\Delta \log f)$ a value of $F=0.07$ is obtained. This value is as expected for a spin glass or a cluster glass, but it is too small for an SMM, thus complex 2: $\mathrm{Ni}_{7}$ is not an SMM. Spin glasses are systems for which spins freeze at random orientations below certain temperature, cluster glasses are systems where instead of single spins, clusters of spins follow this random freezing. The key factors are disorder and frustration, complex 2: $\mathrm{Ni}_{7}$ clearly complies the frustration but also, it lacks important intermolecular interactions that can lead to long range ordering of the $\mathrm{Ni}_{7}$ molecules. In order to rule out $\mathrm{Ni}(\mathrm{OH})_{2}$ impurities in the crushed crystalline sample of 2: $\mathrm{Ni}_{7}$ we studied the magnetic properties of the prepared hydroxide. An out-of-phase ac peak characteristic of $\mathrm{Ni}(\mathrm{OH})_{2}$ appears at $17 \mathrm{~K}$ and shows no frequency dependence. Several samples of 2 : $\mathrm{Ni}_{7}$ that were obtained with higher yields contained some precipitate along with the crystals, large amounts of oxide, and that was reflected in two ac peaks, one centered at $5 \mathrm{~K}$ for 2: $\mathrm{Ni}_{7}$ with strong frequency dependence and one at $17 \mathrm{~K}$ for the $\mathrm{Ni}(\mathrm{OH})_{2}$ impurity.

Magnetic susceptibility data for 4: $\mathrm{Ni}_{3}$ tBu and 5: $\mathrm{Ni}_{3}$ iPr are shown in Figure 8 as $\chi \mathrm{T}$ vs T plots. The $\chi \top$ product values at $300 \mathrm{~K}$ are $4.19 \mathrm{~cm}^{3} \mathrm{~K} \mathrm{~mol}^{-1}$ for $4: \mathrm{Ni}_{3} \mathrm{tBu}$ and $.20 \mathrm{~cm}^{3} \mathrm{~K} \mathrm{~mol}^{-}$ 1 for 5: $\mathrm{Ni}_{3} \mathrm{iPr}$. Both values are in agreement with the expected value for three independent $\mathrm{Ni}(\mathrm{II})$ ions with $\mathrm{S}=1$ and $\mathrm{g}=2$.3. Maxima are observed for both complexes below $25 \mathrm{~K}$, due to Zeeman effects and magnetic anisotropy. Ferromagnetic coupling is to be expected in these $\mathrm{Ni}_{3}$ linear species, each pair of $\mathrm{Ni}(I I)$ ions are bridged by one carboxylato group (mode I in Scheme 1) and two oxygen atoms of chp ligands (mode $\mathrm{V}$ of Scheme 1). The Ni-O-Ni angles, where $\mathrm{O}$ is the oxygen from chp ligand, are between $92^{\circ}$ and $94^{\circ} .{ }^{41}$ Magnetization vs. field plots at $2 \mathrm{~K}$, shown in Figure 9 are in agreement with an anisotropic non-zero spin ground state. 


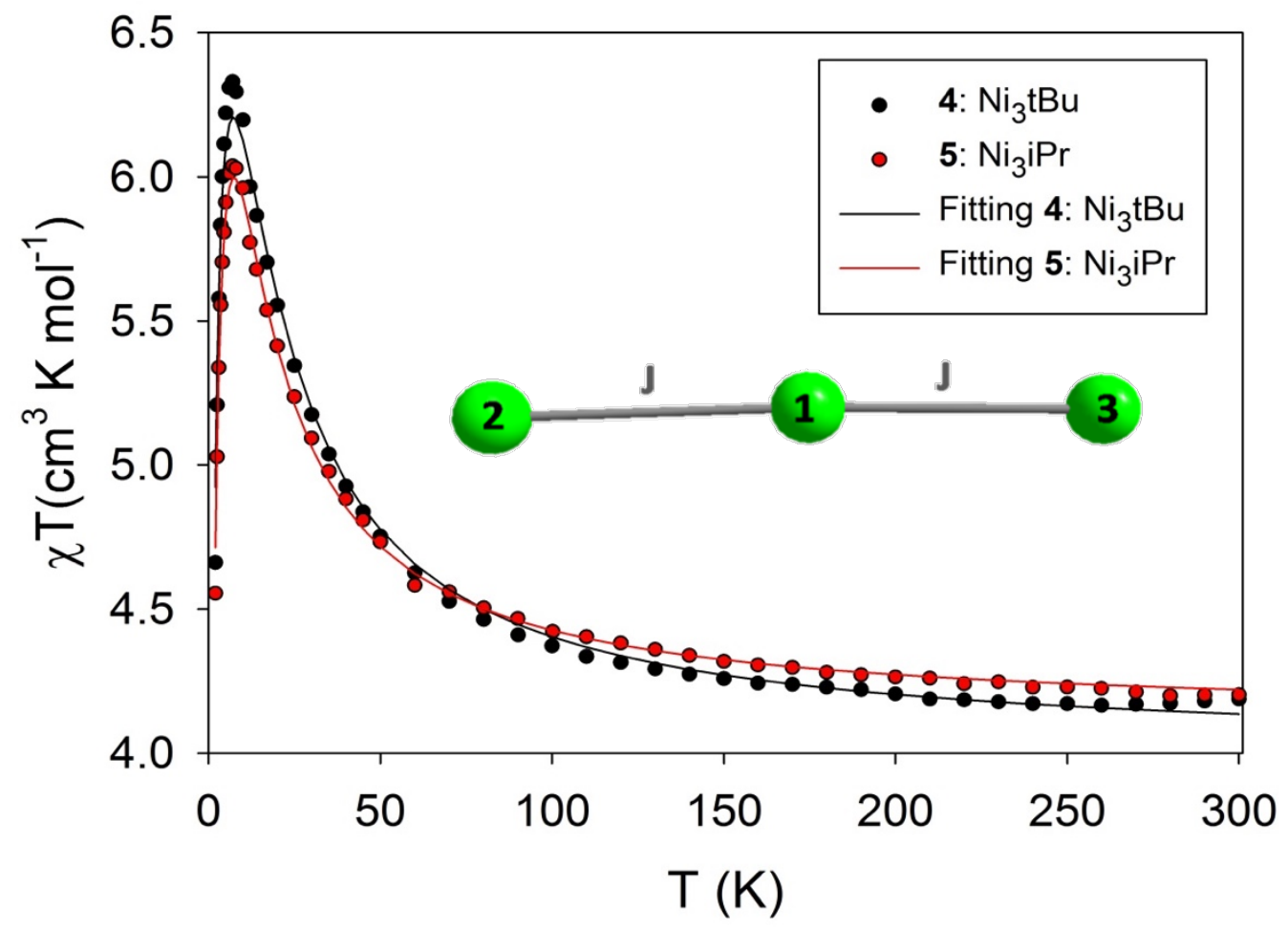

Figure 8. Magnetic susceptibility for complexes 4: $\mathrm{Ni}_{3} \mathrm{tBu}$ and 5: $\mathrm{Ni}_{3} \mathrm{iPr}$. The solid lines are the best fitting to the experimental data (see text for fitting parameters).

The software $\mathrm{PHI}^{42}$ was used to fit simultaneously the susceptibility and the magnetization vs. field data. The susceptibility data can be modelled using a simple spin Hamiltonian with only one exchange constant and including the Zeeman effect and the crystal field on the single ions, as shown in equations 1 and 2.

Eq. 1

$\widehat{H}=\widehat{H}_{E X}+\widehat{H}_{C F}+\widehat{H}_{Z e e m a n}$

Eq. 2

$$
\widehat{H}_{E X}=-J\left[\hat{S} N i_{1} \hat{S} N i_{2}+\hat{S} N i_{2} \hat{S} N i_{3}\right]
$$




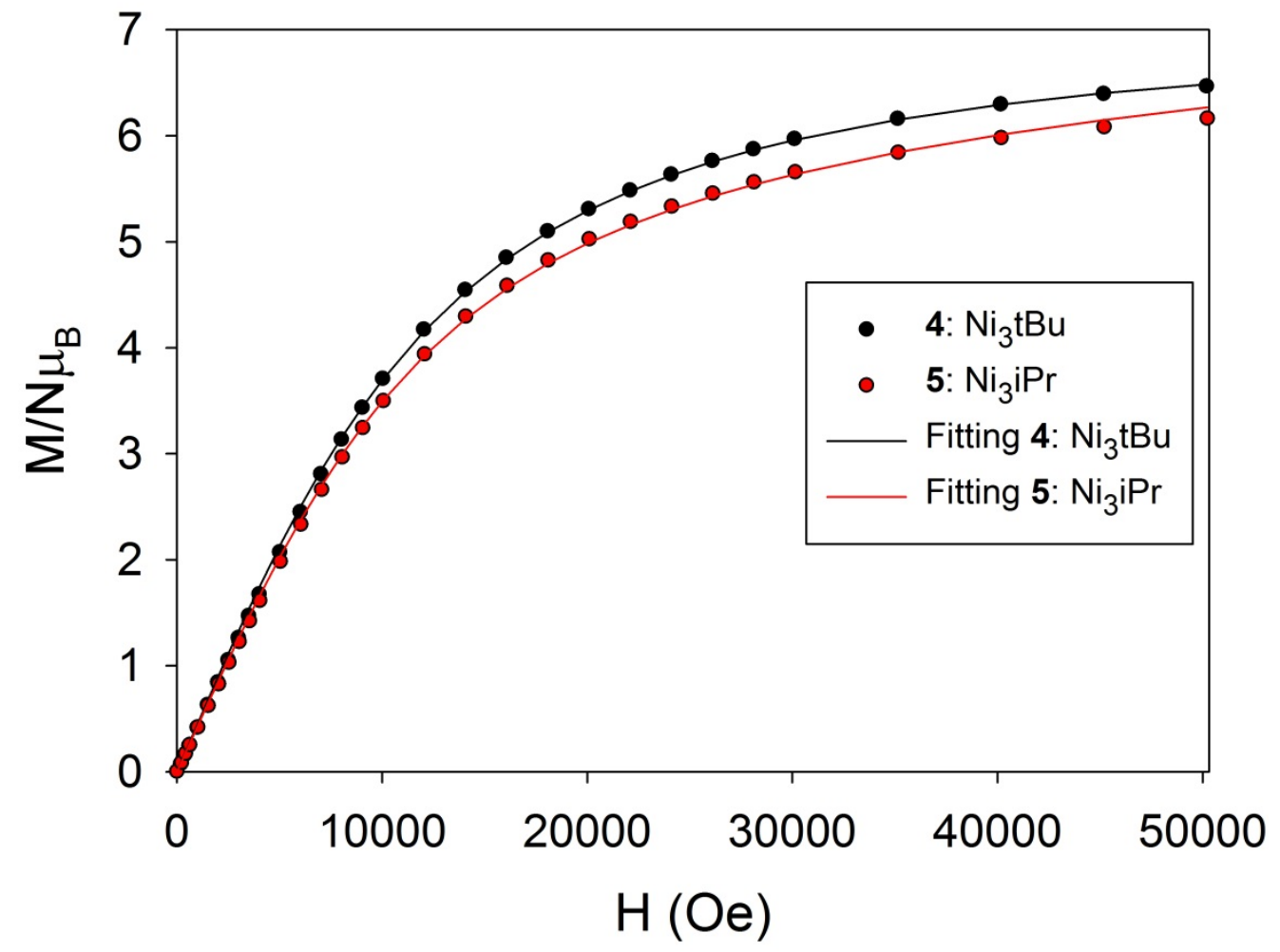

Figure 9. Magnetization vs. field plots for 4: $\mathrm{Ni}_{3} \mathrm{tBu}$ and 5: $\mathrm{Ni}_{3} \mathrm{iPr}$. The solid lines are the best fitting to the experimental data (see text for fitting parameters).

The best fitting is shown in Figure 8 and 9 as solid lines. The $g$ value was fixed as 2.3 for both complexes. The fitting parameters were $\mathrm{J}=3.7 \mathrm{~cm}^{-1}, \mathrm{D}_{2}=\mathrm{D}_{3}=8.02 \mathrm{~cm}^{-1}$ and $\mathrm{D}_{1}=-$ $14.53 \mathrm{~cm}^{-1}$ for $4: \mathrm{Ni}_{3} \mathrm{tBu}$ and $\mathrm{J}=3.8 \mathrm{~cm}^{-1}, \mathrm{D}_{2}=\mathrm{D}_{3}=9.38 \mathrm{~cm}^{-1}$ and $\mathrm{D}_{1}=-11.45 \mathrm{~cm}^{-1}$ for 5 : $\mathrm{Ni}_{3} \mathrm{iPr}$. $\mathrm{D}_{1}$ is the $\mathrm{D}$ value for the central $\mathrm{Ni}(\mathrm{II})$ ion, while $D_{2}=\mathrm{D}_{3}$ are the $\mathrm{D}$ values for the two external $\mathrm{Ni}(\mathrm{II})$ ions. Even though they are not crystallographically equivalent in 
complex 4: $\mathrm{Ni}_{3} \mathrm{tBu}$, the approximation has been accepted to avoid overparametrization of the fitting. For both complexes, the ground state is $S=3$ resulting from ferromagnetic coupling of the three $\mathrm{Ni}(\mathrm{II})$ ions. Magnetization and susceptibility fittings are not optimal to obtain the sign of $D$. the values reported here are those that afford the best agreement with experimental data. Neither 4: $\mathrm{Ni}_{3} \mathrm{tBu}$ nor 5: $\mathrm{Ni}_{3} \mathrm{PPr}$ displayed out-ofphase ac magnetic susceptibility signals, as could be expected for a relatively small spin ground state and all mostly positive single-ion anisotropy parameters.

\section{Conclusions}

Microwave assisted synthesis is a great tool for the coordination chemistry laboratory. We show here that it can be used to prepare polynuclear coordination complexes with good yields and purities. Waste generation in the research laboratory can be minimized using this synthetic method, where only small amounts of solvents are used to extract the solid obtained from the solvent-free microwave reaction.

We tested the solvent-free microwave assisted synthesis with the known complex $\left[\mathrm{Ni}_{7}(\mathrm{chp})_{12}(\mathrm{OH})_{2}\left(\mathrm{CH}_{3} \mathrm{OH}\right)_{6}\right](2)$, and then extended the method to a more complex ligand system. We prepared two new trinuclear $\mathrm{Ni}(\mathrm{II})$ complexes $\left[\mathrm{Ni}_{3}(\mathrm{chp})_{4}(\mathrm{tBuSALOH})_{2}(\mathrm{MeOH})_{5}\right]$ (4) and $\left[\mathrm{Ni}_{3}(\mathrm{chp})_{4}(\mathrm{iPrSALOH})_{2}(\mathrm{MeOH})_{6}\right]$ (5) using solvent-free microwave assisted synthesis. The two $\mathrm{Ni}_{3}$ complexes contain a linear arrangement of $\mathrm{Ni}(\mathrm{II})$ ions that are ferromagnetically coupled.

\section{Acknowledgements}

ECS, LRP acknowledge the financial support from the Spanish Government, (Grant CTQ201568370-P). We acknowledge Dr. Simon S. Teat for data collection of complex 2 at Berkeley ALS.

\section{References}

(1) Winpenny, R. E. P. Dalt. Trans. 2002, 1-10.

(2) Ledezma-gairaud, M.; Grangel, L.; Aromí, G.; Fujisawa, T.; Yamaguchi, A.; Sumiyama, A.; Sañudo, E. C. Inorg. Chem. 2014, 53, 5878-5880.

(3) Sañudo, E. C.; Uber, J. S.; Pons Balagué, A.; Roubeau, O.; Aromí, G. Inorg. Chem. 
$2012,51,8441-8446$.

(4) Coronado, E.; Yamashita, M. Dalt. Trans. 2016, 80, 1517.

(5) Transport, M.; Balestro, F.; Bendiab, N.; Bonet, E.; Bouchiat, V.; Marty, L.; Wernsdorfer, W. 2008.

(6) Sanvito, S. Chem. Soc. Rev. 2011, 40, 3336.

(7) Blake, A. J.; Brechin, E. K.; Codron, A.; Gould, R. O.; Grant, C. M.; Parsons, S.; Rawson, J. M.; Winpenny, R. E. P. J. Chem. Soc. Chem. Commun. 1995, 3, 1983.

(8) Brechin, E. K.; Harris, S. G.; Parsons, S.; Winpenny, R. E. P. Angew. Chemie Int. Ed. English 1997, 36, 1967-1969.

(9) Sanudo, E. C.; Smith, A. A.; Mason, P. V; Helliwell, M.; Aromi, G.; Winpenny, R. E. P. Dalt. Trans. 2006, 1981-1987.

(10) Sañudo, E. C.; Muryn, C. a; Helliwell, M. a; Timco, G. a; Wernsdorfer, W.; Winpenny, R. E. P. Chem. Commun. 2007, 801-803.

(11) Laye, R. H.; Larsen, F. K.; Overgaard, J.; Muryn, C. a; McInnes, E. J. L.; Rentschler, E.; Sanchez, V.; Teat, S. J.; Güdel, H. U.; Waldmann, O.; Timco, G. a; Winpenny, R. E. P. Chem. Commun. (Camb). 2005, 8, 1125-1127.

(12) Sanudo, E. C.; Ribas, J.; Winpenny, R. E. P. New J. Chem. 2007, 31, 1421-1423.

(13) Ishikawa, N.; Sugita, M.; Ishikawa, T.; Koshihara, S.-Y.; Kaizu, Y. J. Am. Chem. Soc. 2003, 125, 8694-8695.

(14) Horii, Y.; Katoh, K.; Cosquer, G.; Breedlove, B. K.; Yamashita, M. Inorg. Chem. 2016, 55, 11782-11790.

(15) Yong, Y. F.; Kowalski, J. a.; Lipton, M. a. J. Org. Chem. 1997, 62, 1540-1542.

(16) Marriott, K. E. R.; Bhaskaran, L.; Wilson, C.; Medarde, M.; Ochsenbein, S. T.; Murrie, M.; Hill, S. Chem. Sci. 2015, 6, 6823-6828.

(17) Kahn, O. Molecular magnetism; VCH Publishers: New York, 1993; Vol. 103.

(18) Blake, A. J.; Grant, C. M.; Parsons, S.; Rawson, J. M.; Winpenny, R. E. P. J. Chem. Soc., Chem. Commun. 1994, 0, 2363-2364.

(19) Andres, H.; Basler, R.; Blake, A. J.; Cadiou, C.; Chaboussant, G.; Grant, C. M.; Güdel, H.-U.; Murrie, M.; Parsons, S.; Paulsen, C.; Semadini, F.; Villar, V.; Wernsdorfer, W.; Winpenny, R. E. P. Chemistry 2002, 8, 4867-4876.

(20) Cadiou, C.; Murrie, M.; Paulsen, C.; Villar, V.; Winpenny, R. E. P. Chem. Commun. 2001, 2666-2667. 
(21) Garlatti, E.; Carretta, S.; Affronte, M.; Sanudo, E. C.; Amoretti, G.; Santini, P. J. Phys. Condens. Matter 2012, 24, 104006/1-104006/9.

(22) Branzoli, F.; Carretta, P.; Filibian, M.; Zoppellaro, G.; Graf, M. J.; Galan-Mascaros, J. R.; Fuhr, O.; Brink, S.; Ruben, M. J. Am. Chem. Soc. 2009, 131, 4387-4396.

(23) Milios, C. J.; Vinslava, A.; Whittaker, a G.; Parsons, S.; Wernsdorfer, W.; Christou, G.; Perlepes, S. P.; Brechin, E. K. Inorg. Chem. 2006, 45, 5272-5274.

(24) Gass, I. a; Milios, C. J.; Whittaker, a G.; Fabiani, F. P. a; Parsons, S.; Murrie, M.; Perlepes, S. P.; Brechin, E. K. Inorg. Chem. 2006, 45, 5281-5283.

(25) Pons-Balagué, A.; Piligkos, S.; Teat, S. J.; Sánchez Costa, J.; Shiddiq, M.; Hill, S.; Castro, G. R.; Ferrer-Escorihuela, P.; Sañudo, E. C. Chemistry 2013, 19, 90649071.

(26) Ledezma-Gairaud, M.; Pineda, L. W.; Aromí, G.; Sañudo, E. C. Polyhedron 2013, $64,45-51$.

(27) Pons-Balague, A.; loanidis, N.; Wernsdorfer, W.; Yamaguchi, A.; Sanudo, E. C. Dalt. Trans. 2011, 40, 11765-11769.

(28) Pons-Balagué, A.; Heras Ojea, M. J.; Ledezma-Gairaud, M.; Reta Mañeru, D.; Teat, S. J.; Sánchez, J.; Aromí, G.; Sañudo, E. C. Polyhedron 2013, 52, 781-787.

(29) Shi, S.; Hwang, J. 2003, 2, 101-110.

(30) Díaz-Torres, R.; Menelaou, M.; Roubeau, O.; Sorrenti, A.; Brandariz-De-Pedro, G.; Sañudo, E. C.; Teat, S. J.; Fraxedas, J.; Ruiz, E.; Aliaga-Alcalde, N. Chem. Sci. 2016, 7, 2793-2803.

(31) Kharisov, B. I.; Dias, H. V. R.; Kharissova, O. V.; Vázquez, A.; Peña, Y.; Gómez, I. RSC Adv. 2014, 4, 45354-45381.

(32) Brown, I. D.; Wu, K. K. Acta Crystallogr. Sect. B Struct. Crystallogr. Cryst. Chem. 1976, 32, 1957-1959.

(33) Petrenko, V. F. Structure of Ordinary Ice Ih - Part I: Ideal Structure of Ice; 1993.

(34) Bagai, R.; Christou, G. Chem. Soc. Rev. 2009, 38, 1011-1026.

(35) Sessoli, R.; Tsai, H.-L.; Schake, A. R.; Wang, S.; Vincent, J. B.; Folting, K.; Gatteschi, D.; Christou, G.; Hendrickson, D. N. J. Am. Chem. Soc. 1993, 115, 1804-1816.

(36) Physik, I.; Mainz, U.; Mainz, D.-; Germany, W.; Young, A. P. 1986.

(37) Mydosh, J. A. Reports Prog. Phys. 2015, 78, 052501-052526. 
(38) Shaw, R.; Tidmarsh, I. S.; Laye, R. H.; Breeze, B.; Helliwell, M.; Brechin, E. K.; Heath, S. L.; Murrie, M.; Ochsenbein, S.; Güdel, H. U.; McInnes, E. J. L. Chem. Commun. 2004, 4, 1418-1419.

(39) Carretta, S.; Santini, P.; Amoretti, G.; Affronte, M.; Candini, A.; Ghirri, A.; Tidmarsh, I. S.; Laye, R. H.; Shaw, R.; McInnes, E. J. L. Phys. Rev. Lett. 2006, 97, $1-4$.

(40) Goremychkin, E. a.; Osborn, R.; Rainford, B. D.; Macaluso, R. T.; Adroja, D. T.; Koza, M. Nat. Phys. 2008, 4, 766-770.

(41) Halcrow, M. A.; Sun, J.; Huffman, J. C.; Christou, G. Inorg. Chem. 1995, 4, 41674177.

(42) Chilton, N. F.; Anderson, R. P.; Turner, L. D.; Soncini, A.; Murray, K. S. J. Comput. Chem. 2013, 34, 1164-1175. 